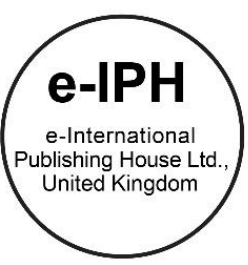

\title{
Satisfaction Level of Progressive Additional Lens (PALs) Wearers
}

\author{
Nur Aresya Ahmad Najmee, Noor Halilah Buari, Rabiatun Mujari, Muhammad Irwan Rahman \\ Optometry, Faculty of Health Sciences, \\ Universiti Teknologi MARA, 42300 Bandar Puncak Alam, Selangor, Malaysia \\ aresyanajmee@puncakalam.uitm.edu.my
}

\begin{abstract}
The number of presbyopia is increasing worldwide with highly reported on an inadequate correction, which can reduce the visual satisfaction. A survey was conducted to study the level of vision satisfaction between the quality of vision and symptoms reported by progressive addition lens (PALs). Sixty questionnaires were mailed to the (PALs) wearers aged between 40 years and above from Universiti Teknologi Mara (UiTM) Vision Care. The strongest correlation was found between the quality of vision at intermediate viewing with total satisfaction on seeing grocery shelves and computer screen with $p<0.001$. PALs wearers priority and needs should be considered in selecting the appropriate lens design to be matched for required tasks.
\end{abstract}

Keywords: Level of satisfaction; quality of vision; multifocal lens; progressive additional lens.

eISSN: 2398-4287@ 2017. The Authors. Published for AMER ABRA by e-International Publishing House, Ltd., UK. This is an open access article under the CC BYNCND license (http://creativecommons.org/licenses/by-nc-nd/4.0/). Peer-review under responsibility of AMER (Association of Malaysian Environment-Behaviour Researchers), ABRA (Association of Behavioural Researchers on Asians) and cE-Bs (Centre for Environment-Behaviour Studies), Faculty of Architecture, Planning \& Surveying, Universiti Teknologi MARA, Malaysia.

https://doi.org/10.21834/e-bpj.v2i6.999

\subsection{Introduction}

Presbyopia affects the quality of life (Patel \& West, 2007). Presbyopia is the most common physiological change that occurs in the most adult eye and expected to impact billions of people worldwide (Chu, 2010). According to Laviers et al., (2009), presbyopia is projected to impact 1.04 billion of people in which 517 million people were left inadequately fixed. Furthermore, (McDonnell et al., 2003) suggested that the association of presbyopia have an adverse impact towards the life of United States population. The normal young eyes can easily focus on near or distant objects (Werner et al., 2000). This ability diminished towards old age.

According to Helmholtz's theory, the cause of presbyopia is due to the loss of elasticity of the crystalline lens in which the changes or contraction in the ciliary muscle and choroid become less efficient with age. The loss of elasticity will cause the lens to resist in changing its shape and focus on near and distant objects (Chu, 2010). Due to ageing, the capability of reading small prints at a normal distance decreases as blur increases. Progressive degeneration combined with inadequate illumination, as light affects the human vision (Wahab \& Zuhardi, 2013), normal size print will soon diminish. The onset of presbyopia is considered to occur when the amplitude of accommodation has decreased to $5.00 \mathrm{D}$ or less (Grosvenor, 2007). As the amplitude of the accommodation diminished, the range of clear vision at near will reduce due to the disturbance and difficulties in more frequent or demanding near vision tasks.

eISSN: 2398-4287C 2017. The Authors. Published for AMER ABRA by e-International Publishing House, Ltd., UK. This is an open access article under the CC BYNCND license (http://creativecommons.org/licenses/by-nc-nd/4.0/). Peer-review under responsibility of AMER (Association of Malaysian Environment-Behaviour Researchers), ABRA (Association of Behavioural Researchers on Asians) and cE-Bs (Centre for Environment-Behaviour Studies), Faculty of Architecture, Planning \& Surveying, Universiti Teknologi MARA, Malaysia.

https://doi.org/10.21834/e-bpj.v2i6.999 
A self-administered questionnaire by the National Eye Institute of Refractive Error Quality of Life was conducted and found out that inadequate optical correction of people with presbyopia has been found to give adverse effects on their health-related quality of life (Chu, 2010). The daily life of people suffering from visual impairment can be affected (Malinovska \& Majerova, 2015). An effective optical correction by using spectacles is one of the solutions to remediate presbyopia. It remains as the most shared and cost-effective presentation worldwide (Marmamula et al., 2013). By prescribing reading additions based on patient's age would be the most successful method to determine correction addition required for the presbyopic patient (Leary \& Evans, 2003).

There are several choices of prescription or procedure to correct presbyopia. For example, a single vision lens for near correction. Another type of lenses such as bifocal or trifocal lenses, progressive or multifocal lenses, progressive contact lens or surgery can also be used to accommodate presbyopic patients. Initially, the majority of presbyopes were prescribed to use progressive addition lenses (PALs), which followed by bifocal or trifocal spectacles (Chu, 2010). Nevertheless, the use of progressive addition lens (PAL) is the ideal spectacle correction for presbyopia due to the property less distortion, which can provide a continuous progression in power for clear vision at all distances (Lynn, 1998). The property of progressive lens on PALs, enables a continuous clear vision at a distance, intermediate and near in which the dioptric power will gradually increase along the lens surface from the upper to the lower portion (Odjimogho, 2004). Gradual changes in plus power for about 0.12D steps can barely eliminate the jumping image due to the rotation of distance to near portion, which caused by the seamless transition of power. Furthermore, the design of PALs in regard of the curves, known as curvature, is taken into consideration, as to allow the customisation on the wearer habits and characteristics such as occupation, age, head movements and relative velocity (Savio, Concheri, \& Meneghello, 2011).

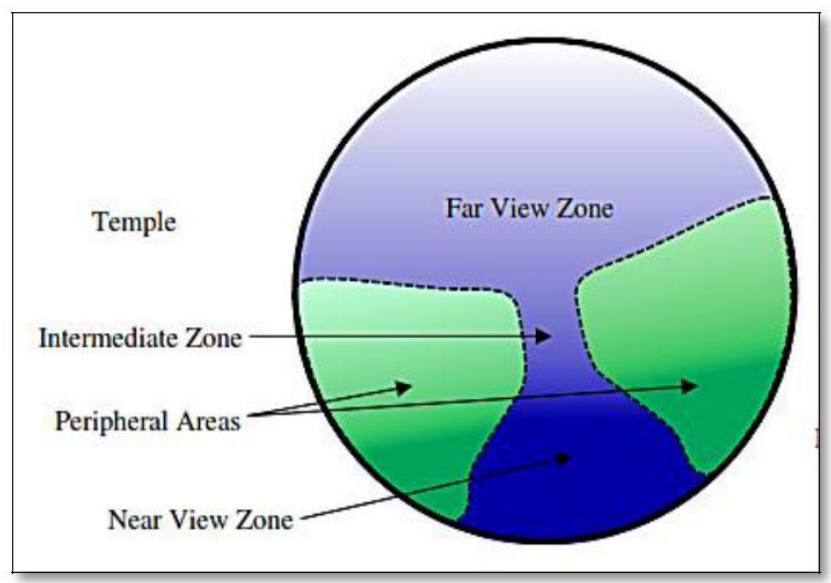

Figure 1.1 Arrangement of a PAL lens.

The majority of PALs wearers have the acceptance rate at $90 \%$ or more due to the comfortability and the quality of vision that PALs provided (Hons, 2008). It has become one of the most competent presbyopic management and an excellent choice for presbyopia wearer as compared to bifocal lenses. The high acceptance rate of PALs can be due to the elimination of imaginary lines and jumping images in which reduce the sudden change in the prismatic and increase the comfortability of the wearers (Walsh, 2001). Odjimogho (2004) surveyed 106 PALs wearers aged between 37 to 66 years old. $69.8 \%$ of patients have a high rate of comfortability with their PALs. Younger patients have achieved more comfortable fit as compared to older patients. This may occur due to the easier adaptation of the early presbyope as compared to the late presbyope. A previous study by Han et al., 2011, has compared patients" satisfaction with progressive lenses with other types of presbyopic correction. They revealed pout that most the subjects involved has were satisfied with progressive lenses rather than other type of lenses (Han et al., 2011). Overall, the multi-design lens scored the highest in the areas of quality of vision, ease of adaptation and patient satisfaction (Lynn, 1998). Moreover, cosmetically, PALs offer a desirable additional power without the lines and ledges that fundamentally „blend" the transition between distance and near zones (Meister \& Fisher, 2008). The blending is by a various amount of astigmatism that oriented at the oblique axis. The ability to alter the dimension from the distance to intermediate and near were also influence the high comfortability with PALs wearers. It represented the overlapping of multiple individual focal points, where each have their own range of clear vision, hence providing a single, broad expanse of clear vision from infinity to near distance (Gispets, Pujol, \& Vilaseca, 2011). Clear vision is possible to some extent at all distances and certainly increased the quality of vision (Walsh, 2001). According to Gime, 2008, although bifocal lenses were more appreciated for their near field of view, progressive lenses have had a very high success (97\%) since the 1970s (Gime, 2008). A previous study by Spaulding (1981), involving 48 multifocal candidates and their preferences of multifocal lens design. $52 \%$ preferred PALs lenses as compared to bifocal design (48\%) (Lynn, 1998). According to (Chu, 2010), one study demonstrated that up to $92 \%$ of previous bifocal wearers preferred progressive addition lenses (PALs) when given a choice between PALs and bifocal lenses following a trial of PALs. The line on bifocals is not particularly attractive for younger presbyopes. Ninety-two percent of patients involved in the study by Boroyan et al. (1995) preferred PALs as compared to a lined multifocal due to the cosmetic purposes (Lynn, 1998). The success of the visual performances with PAL spectacles was correlated with the optics of the lenses, the fit of the frame and the position wear including eyes and head movement for visual tasks at a different viewing distance and the individual characteristics of the patient. Hence, the adaptation and satisfaction PALs have been hampered by several problems. The primary disadvantage of PAL 
is the restricted optical zones. This makes reading at both intermediate and near distances a problem (Spencer \& Ciuffreda, 2002). Restriction of this optical zone will lead to the increment frequency of the compensatory head movement to get clear vision. Furthermore, the prismatic effect of the lateral sides of PALs. This will cause the presence of unwanted peripheral astigmatism, which is induced by the continuous change in power through the lens. PALs wearers may be aware of the lateral image blur that can adversely affect the success of the adaptation process (Mok, Chung, \& Kwok, 2011). Thus, most of the PALs wearers complained of vertigo and dizziness when changing gaze horizontally (Suemaru, Hasebe, \& Ohtsuki, 2008). PALs wearers were also needed to view the appropriate part of the lens to obtained clear vision depending on the distance of the object. Moreover, the progressive lens costs more than other types of correction lenses for presbyopia. Consequently, due to all of these problems, some patients are not satisfied enough with their spectacle correction. Therefore, a survey of patients" satisfaction on wearing progressive additional lenses was conducted. In this study, we systematically review patients' feedback on progressive additional lenses provided by UiTM Vision Care regarding the quality of vision and associated symptoms occurred. It is fundamental to evaluate the satisfaction level of vision among presbyopic patients with PALS as well as to enhance the services provided by UiTM Vision Care.

\subsection{Methodology}

\subsection{Research Design}

A cross sectional survey design was chosen to answer the research aims and objectives. Data was collected at a particular time in one session for a defined population.

\subsection{Research Settings and Participants}

Sixty respondents aged between 40 years old and above were selected from UiTM Vision Care (optometric clinic and practice in Universiti Teknologi MARA). Those who were wearing progressive addition lens for other reasons such as myopia or accommodation were excluded from this research. Respondents were selected from patients" records and enlisted using convenience and availability sampling method. Patients" records were obtained by accessing their archived receipt for the purchase of progressive additional lenses (PALs) that was prescribed from UiTM Vision Care. The selection was based on the patients" prescription from February 2014 through February 2015.

\subsection{Instrument}

A questionnaire was adopted from The Ohio State (DAI-B 59/08, p. 4217, Feb 1999) to evaluate the satisfaction level of visual performance based on respondents' daily activities. The questionnaires were divided into three parts; namely (1) demographic details, (2) respondents feedback, and (3) symptoms reported by the PALs wearers. The questionnaire was given via email, post and by other types of communication services. Demographics questions were developed to collect the respondents' information. The questions regarding visual performances at distance viewing, intermediate viewing and near vision with the total satisfaction of progressive additional lens (PALs) prescribed were calculated using a Likert scale. Symptoms occurred while wearing the PALs was also recorded in the questionnaires. The Likert scale has been used as it is a simple, reproducible, quick and reliable in measuring the patients" satisfaction level (Hiraoka et al., 2009). The questionnaires had 10-point Likert responses scales ranging from 0 , which represented as 'totally unacceptable' to 10 which described as 'excellent' for part (2). Except for part (3) which is related to symptoms experienced by respondents, the responses scale ranging from 0-10 which is 'extremely bad' to 'none' respectively. The scores were converted into percentages, the higher the rate, the level of satisfaction respondents using the PALs was assumed as increased. Total satisfaction of PALs wearer was determined by adding all responses in part (2) which give a total score of 100.

\subsection{Data Analysis}

All data were analysed using SPSS software version 21.0. The descriptive data respondents were shown regarding the mean and standard deviation. Satisfaction level was analysed using linear regression to determine the correlation between the qualities of vision with total satisfaction. As for the relationship between quality of vision, wearing hours and associated symptoms with total satisfaction, Spearman rank correlation was used. Findings with a $p$-value $<0.05$ were considered to be statistically significant.

\subsection{Ethics}

The study was approved by Research Ethics Committee of Universiti Teknologi MARA (UiTM). The aims and objectives of the study were explained to all respondents, and informed consent forms were obtained.

\subsection{Result}




\subsection{Respondents profile}

The questionnaires were mailed out to the sixty respondents that were selected from UiTM Vision Care. From the sixty questionnaires, only thirty-two questionnaires were given back, which gave the total of $53.3 \%$ of response rate. However, due to the invalid response and the involvement of glaucoma disease by the respondents, another two questionnaires were excluded. Only thirty questionnaires were used for further analysis, which gave a total of $50 \%$ response rate.

The socio-demographic data of the respondents were tabulated in Table 3.1 which comprise of gender, ethnic, age, and salary range. $97 \%$ of the respondents were Malay while only $3 \%$ of the respondents were non-Malay. The distributions of male to female respondents were $33 \%$ and $67 \%$ respectively. The majority of the respondents were aged between 51 to 60 years old which comprises of $54 \%$ of the total respondents while only one respondent was aged at 40 years old $(3 \%)$. The other $43 \%$ of the respondents were aged between 41 to 50 years old (30\%) and above 61 years old (13\%). Also, $47 \%$ of the respondents earn between RM 4501 and above per month, followed by both RM 1501-3000 (20\%) and less than RM $1500(20 \%)$ per month, while $13 \%$ of the respondents that have the frequency of 4 earns between RM 3001-4500 per month.

Table 3.1: Socio-demographic characteristics of the respondents

\begin{tabular}{lcc}
\hline Demographic data & Frequency & Percentage (\%) \\
\hline Gender & 10 & 33 \\
Male & 20 & 67 \\
Female & & \\
\hline Ethnic & 29 & 97 \\
Malay & 1 & 3 \\
Non-Malay & & \\
\hline Age & 1 & 3 \\
40 years old & 9 & 30 \\
41 to 50 years old & 16 & 54 \\
51 to 60 years old & 4 & 13 \\
61 years old and above & & 20 \\
Salary & 6 & 20 \\
<RM1500 & 6 & 13 \\
RM1501 to 3000 & 4 & 47 \\
RM3001 to 4500 & 14 &
\end{tabular}

\subsection{Quality of Vision, Wearing Hours and Symptoms Reported and Total Satisfaction of PALs wearers.}

Based on initial assessment, all of the respondents have healthy eyes with normal corrected vision. Hence, high qualities of vision and high levels of patients" satisfaction were most appreciated after the prescription of the progressive additional lens (PALs). The feedbacks from the respondents were assessed based on two key factors, which were the quality of vision at the different viewing area and the symptoms reported after the application of PALs. Figure 3.1 and Figure 3.2 shows the mean for the quality of vision at the different viewing area, and the mean value for symptoms reported related to the use of progressive additional lens respectively.

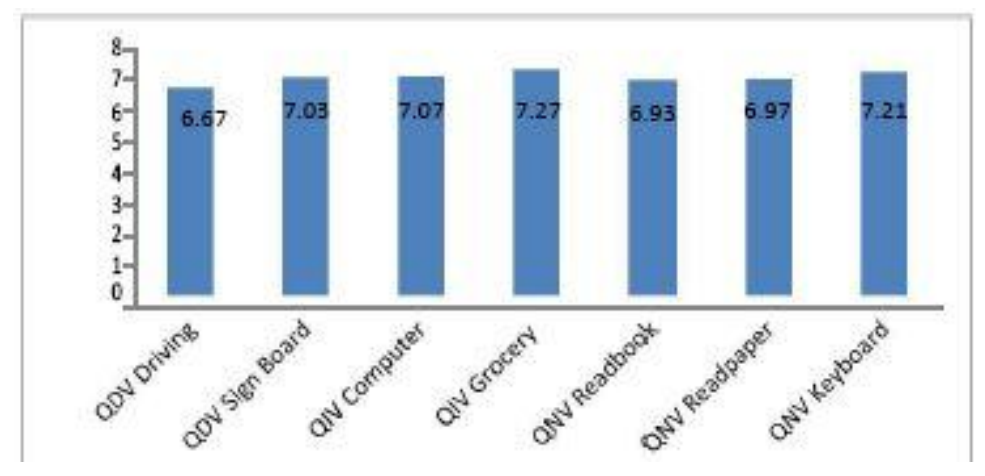

Figure 3.1 Mean quality of vision at the different viewing area. 


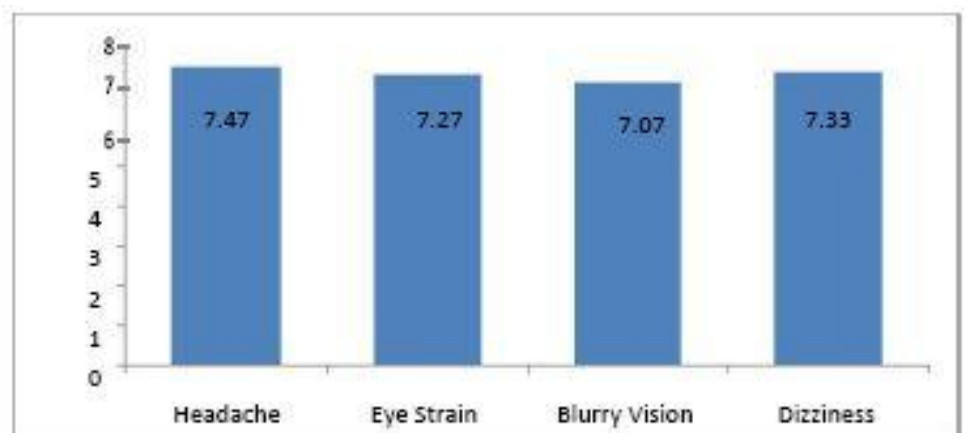

Figure 3.2 Mean symptoms reported associated with PALs.

The mean value provided is directly proportional to the satisfaction value. The highest mean for quality of vision (Figure 3.1) reported by the respondents is by seeing grocery shelves at intermediate viewing $(7.27 \pm 1.84)$, followed by seeing keyboard computer at near $(7.20 \pm 2.02)$, seeing computer monitor at intermediate viewing $(7.07 \pm 2.05)$, seeing signboard at distance viewing $(7.03 \pm 1.85)$, reading paper on a chair $(6.97 \pm 2.19)$, reading book at table $(6.93 \pm 2.16)$. The lowest quality of vision reported is by viewing at a distance while driving $(6.67 \pm 2.45)$. The descriptive result of wearing hours shows that the mean is $9.47 \pm 5.698$ hours. These high wearing hours indicates that most of the PALs wearer wore it for almost half of their day to do their daily activities.

In contrast, the mean value provided by the symptoms is indirectly proportional towards the satisfaction value. The highest reported symptoms related to the use of PALs lenses were blurry vision with a mean of $7.07 \pm 2.60$, followed by eye strain (7.27 \pm 2.55$)$, dizziness $(7.33 \pm 2.86)$ and headache $(7.47 \pm 2.93)$. A high mean value for the symptoms is because; most of the patients rate their symptoms as "10". The value "10" indicates that none of the symptoms to be felt by the patients.

\subsection{Correlation of Quality of Vision, Symptoms with Total Satisfaction Level of PALs Wearer.}

The relationship between the quality of vision at the different viewing area and the total satisfaction were obtained by using Spearman Correlation. The test revealed that the correlation between the quality of vision for driving and seeing signboard at a distance is positively correlated with the total satisfaction, and both were statistically significant, having the value of $p<0.05$ (Figure $3.3(\mathrm{~A})$ and $(\mathrm{B}))$. Out of 10 questions regarding the quality of vision, the correlation of quality of vision during driving showed the lowest in the ranking of total satisfaction.

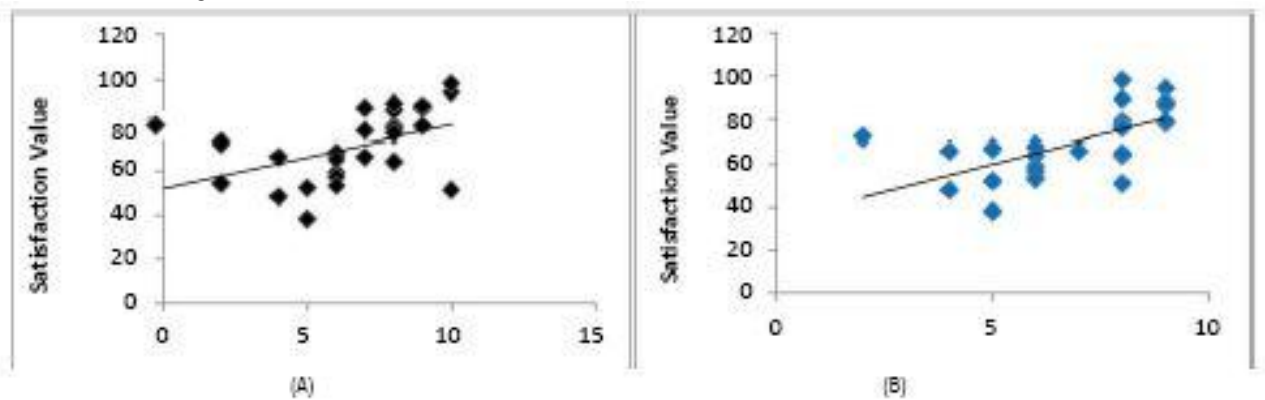

Figure 3.3: Scatter plot of correlation between qualities of vision at a distance with total satisfaction. (A) Correlation between qualities of vision of driving with total satisfaction (B) Correlation between qualities of vision of seeing a signboard with total satisfaction.

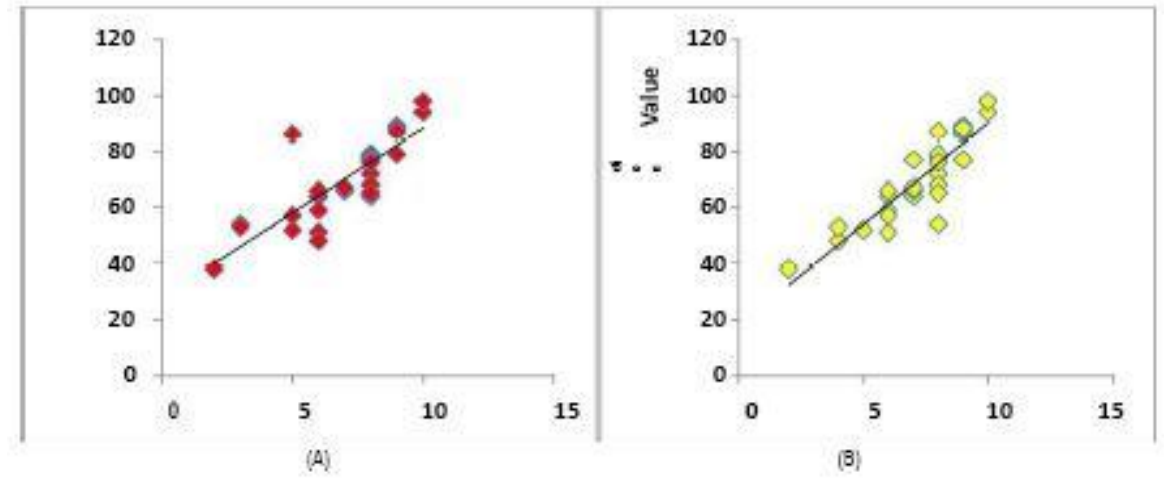

Figure 3.4: Scatter plot of correlation between qualities of vision at intermediate with total satisfaction. (A) Correlation between qualities of vision of seeing computer monitor with total satisfaction (B) Correlation between qualities of vision of seeing grocery shelves with total satisfaction. 
The correlation between the quality of vision at the intermediate viewing for seeing computer monitor and seeing grocery shelves are highly correlated to the total satisfaction Figure 3.4 (A) and (B). Higher total satisfaction was associated with higher level of quality of vision. Higher scores indicated a better clarity of the visual performance. The correlation between the quality of vision and total satisfaction is the highest at intermediate viewing compared to others.

The correlation between the quality of vision at near viewing for seeing computer keyboard, reading paper while sitting on a chair and reading a book on a table, are highly correlated to the total satisfaction, and it is statistically significant to each other as shown in Figure $3.5(A),(B)$ and $(C)$. The highest quality of vision was seeing computer keyboard, followed by reading the paper on a chair and reading a book at the table. Table 3.2 summarises the correlation of the quality of vision with their respective satisfaction values.
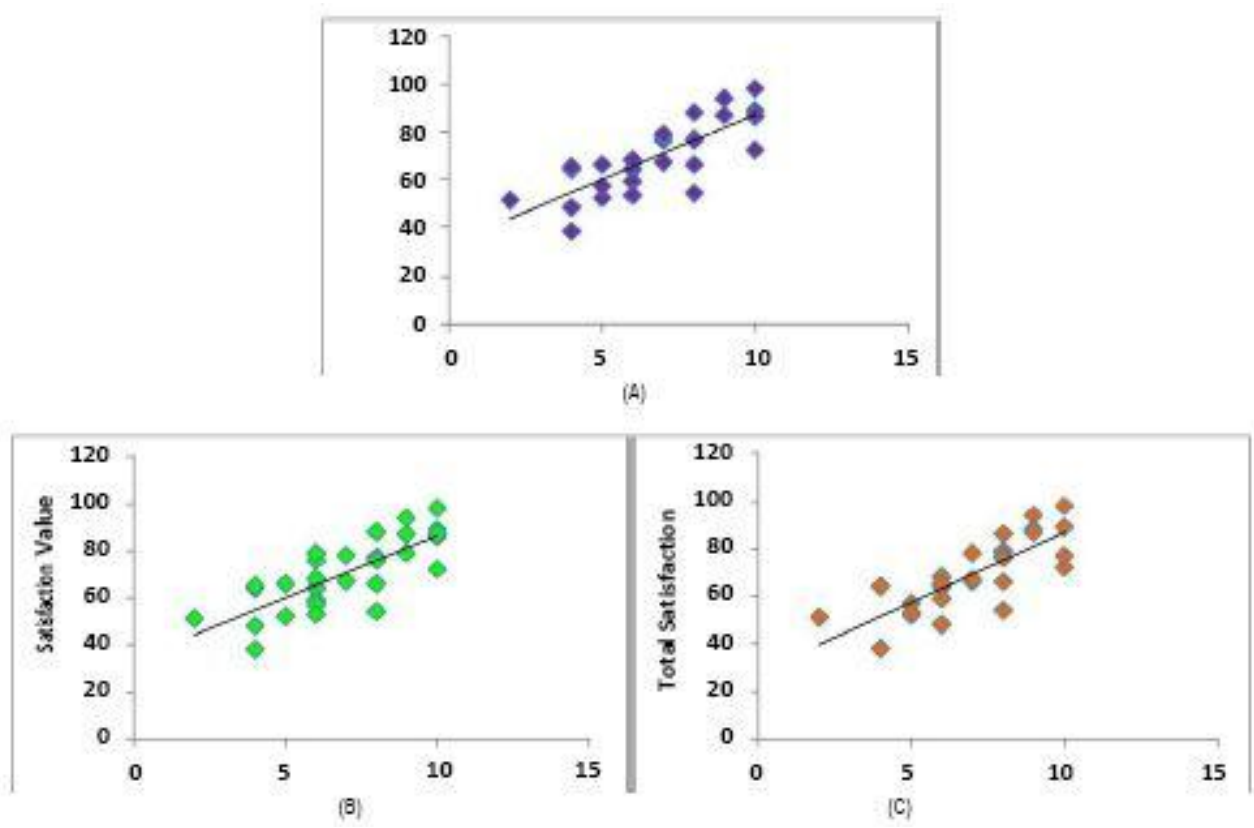

Figure 3.5: Scatter plot of correlation between qualities of vision at near with total satisfaction. (A) Correlation between qualities of vision of seeing computer keyboard with total satisfaction (B) Correlation between qualities of vision of reading the paper at the chair with total satisfaction. (C) Correlation between qualities of vision of reading book at a table with total satisfaction.

Table 3.2: Summary on the correlation of quality of vision at distance, intermediate, and near regards with the tasks required.

\begin{tabular}{lll}
\hline Quality of Vision & Regression $(\mathbf{r})$ & p value \\
\hline At Distance & & \\
Driving & 0.574 & 0.001 \\
See signboard & 0.728 & 0.000 \\
\hline At Intermediate & & \\
See computer monitor & 0.844 & 0.000 \\
See Grocery shelves & 0.844 & 0.000 \\
\hline Near & & \\
Reading books & 0.803 & 0.000 \\
Reading paper at chair & 0.791 & 0.000 \\
See keyboard & 0.833 & 0.000 \\
\hline
\end{tabular}

There was a statistically significant difference of the correlation between each symptom and their total satisfaction, which was analysed by Spearman Correlation. The mean rating for each symptom in the questionnaire did not appear to differ between each other. The correlation between the symptoms and satisfaction value were shown in Figure 3.6 and Table 3.3.

Table 3.3: Summary on the correlation of the symptoms.

\begin{tabular}{lll}
\hline \multicolumn{1}{c}{ Symptoms } & Regression $(\mathbf{r})$ & p value \\
\hline Headache & 0.369 & 0.045 \\
Eye strain & 0.475 & 0.008 \\
Blurry vision & 0.701 & 0.000 \\
Dizziness & 0.437 & 0.016 \\
\hline
\end{tabular}




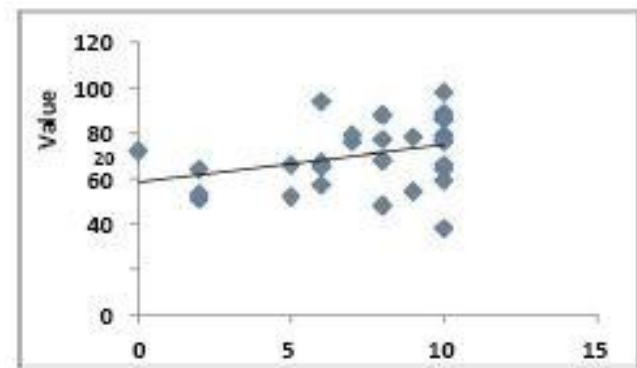

(A)

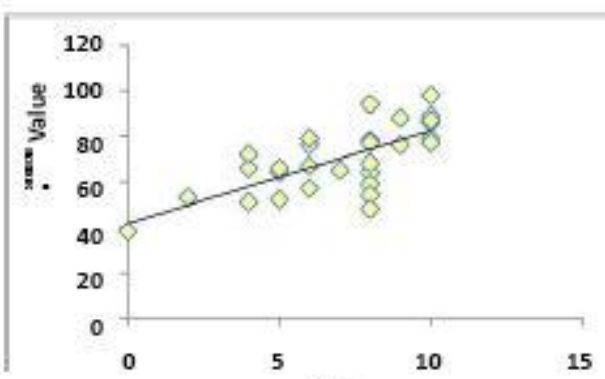

(c)

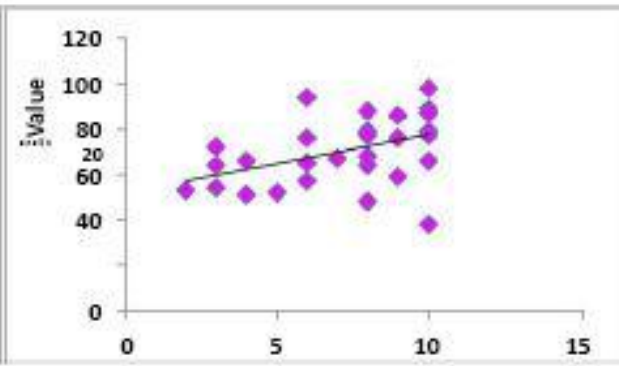

(B)

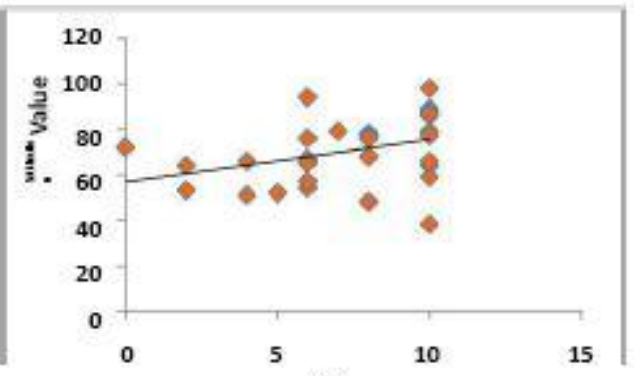

(D)

Figure 3.6 Scatter plots of associated symptoms with total satisfaction. (a) Headache with total satisfaction, (b) Eyestrain with total satisfaction, (c) Blurred vision with total satisfaction and (d) Dizziness with total satisfaction

\subsection{Discussion}

\subsection{Quality of Vision at Total Satisfaction.}

Linear regression was performed to determine the correlation between the qualities of vision with the total satisfaction (Figure 3.4 and 3.5). Slopes of the regression lines are positive with the increase in score of the total satisfaction for each of the task. As for the relationship between the qualities of vision with their total satisfaction level and the results of the Spearman rank correlation test, it shows that the quality of vision was significantly correlated with the patient satisfaction. It can be said that different viewing area or different tasks to be a major factor that affects the satisfaction level as people seek for best correction lenses to help in improving their visual acuity and improving their quality of life.

Measuring the variances at different viewing areas has proven to affect the visual task performance (J. Sheedy, Hardy, \& Hayes, 2006). Hence, patients should be aware that, different zones" widths and areas across the lens were designed to satisfy their visual performances. The result shows that the level of visual satisfaction was highest at the intermediate as compared to the distance and the near viewing. The correlation between these qualities of vision at intermediate viewing with total satisfaction gave the highest correlation regression as shown in Table 3.2. The tasks that require the respondents to use their lens in the intermediate zones also show positive linear regression line and higher correlation coefficient value. This corroborates with Gispets et al., (2011) and Spencer \& Ciuffreda, (2002) where the stimulus becomes sufficiently cramp and precise to be felt within the clear field of the view at the intermediate channel. This will reduce the shift of the head movements and cause it to become a more desirable yet closer match to the normal eye fixation magnitudes (J. E. Sheedy, 2004). Moreover, depth-of-focus in this area offers a better compromise in which sharper retinal images produced to be corresponding with the objects. Interestingly, related to this, it was reported that the performance of PALs is equivalent to the performance of single vision lenses (Spencer \& Ciuffreda, 2002). The intermediate viewing provides a clear vision non-stepwise and corresponds to the wide visual distance range. It greatly enhances the capacity of the visual field at that segment (Sugarman, 1994). Nonetheless, the main consideration of the PALs effectiveness at the intermediate viewing needs to be related to the task itself.

The result of high satisfaction with significant positive linear correlation was also found at the near viewing on the tasks like reading a book on the table, reading the paper on a chair and seeing the keyboard (Figure 3.5). During reading, the eye does not move in an orderly manner. They pause, move backwards and jump from one point to another; hence require a high level of accommodation (Batemanazan et al., 2014). These findings support the prediction by the previous studies where reading involving size print would require the use of the clearest portion of the lens and the clarity of vision is ideal at the centre of the near zone (Lynn, 1998). However, this was contradicted by the study done by Gime, (2008), the distance vision tasks have higher satisfaction, but for near vision, the task received the lowest score.

High satisfaction can be barely assumed as most wearers were either able to tolerate well with the eye movement required during near task or adapt on the preferred lens design. This may happen due to the choices of the lens design for the suitable daily task were more toward near tasks compared to distance tasks (R.Cited, 2004). However, according to Chu, (2010), PALs wearer require a significantly higher head movements when reading a near text which diminished the adaptation and satisfaction level of the PALs 
wearers. Hence, it contradicted with the result gathered in this study due to the different type of statistical analysis used which is an analysis of variance (ANOVA).

At the distance viewing, the result shows the lowest level of visual satisfaction as both require higher visual demands such as driving and seeing signboard (Figure 3.3 (a) and (b)). During driving, by viewing an object at a distance paired with vision disturbance; peripheral blur, unwanted astigmatism and distortion. Han et al. (2011) reported that progressive additional lens (PALs) wearer was more satisfied as compared to the use bifocal lens. However, most of them were uncomfortable with distortion at the peripheral vision. A study conducted by Ellison, (2012) justified the same effect on PALs wearers. Activities such as driving or walking by using progressive additional lens cause the vision to appear to oscillate at the sides. This scenario rose due to the aberration and unwanted astigmatism at the peripheral section of the lens while making the higher visual demand (Spencer \& Ciuffreda, 2002). Peripheral astigmatism in the progressive lens has been found to be significant in its axis and magnitude (Hendicott, 2007). This peripheral astigmatism can change the power along the vertex line of the PALs progression. Thus wearers may experience astigmatism with the occurrence of blur when the eye moves toward the other different viewing areas.

\subsection{Symptoms and Total Satisfaction}

Most PALs wearers reported being comfortable with their lenses as the data obtained shows the least of complaints and symptoms with the high level of satisfaction. Blurry of vision is the most noticeable symptom that lowered the level of total satisfaction and shows the most positive regression lines among others (Figure 3.6). Poor adaptation, changes of power profile in term of magnification, astigmatism or aberration along the PALs lines can be the main causes of blurry vision. A similar result is obtained from the quality of vision at distance viewing which shows the lowest satisfaction. This likely due to the optical design of the PALs as progressive additional lens require gradual changes of distance to near area which caused unwanted distortion through the lower lens periphery (Chu, 2010). However, there were no significant differences between the symptoms. Also, a high correlation was recorded between the symptoms reported with the total satisfaction ( 0.7 and above) with the PALs dispensed. This indicates most wearer can use their PALs without any significant visual problems in their daily activities.

\subsection{Conclusion}

Despite their limitation, progressive additional lenses are the best option and represent the rigid multifocal correction for a large share of the presbyopic population. Even though it had been introduced to the public many years ago; approximately 40 years, however, the improvement of the PALs design are consistently released as there was always a high demand for needs of the better understanding towards its progressive surface (Pope, 2000). The improvements are used to enhance the antagonist lenses qualities together with wearerse adaptation and happiness. Thus, the result from this study can benefit all eye-care practitioners especially optometrists to improve the quality of servicing progressive additional lens by providing the information regarding the quality of vision that is positively correlated with the level of total satisfaction for progressive addition lenses delivered by UiTM Vision Care. It is reasonable for the quality of vision at a different area or different tasks to be major factors that affect patient satisfaction level because wearers seek the best correction to help to improve the visual acuity and their quality of life.

The eye-care practitioners should aware of the PALs wearers ${ }^{\text {ee }}$ priority and requirements in selecting the appropriate lens design that matches with the tasks required. Hence, the study can act as a stimulus for better research in the future especially in ophthalmic industry to develop and market PAL designs based on the wearerse specific visual needs and tasks. Additionally, by time to time, due to advance in technology, there will be some improvement in PALs designs, potentially reducing the possibility of symptoms, hence increasing satisfaction level among PALs wearers in the future.

\section{Acknowledgements}

The authors wish to thank UiTM Vision Care and Faculty of Health Sciences, Universiti Teknologi MARA (UiTM) for permission to conduct the study and to all participants in the study.

\section{References}

Batemanazan, V., Jaafar, A., \& Salehuddin, K. (2014). A Comparative Study on the Eye Movement Patterns in Malay- English bilingual readers. Procedia - Social and Behavioral Sciences, 118, 229-234. https://doi.org/10.1016/j.sbspro.2014.02.031

Boroyan HJ, Cho MH, Fuller BC, Krefman RA, McDougall JH, Schaeffer JL, Tahran RL. (1995). Lined multifocal wearers prefer progressive addition lenses. J Am Optom Assoc. 66(5):296-300

Chu, B. S. (2010). The impact of presbyopic spectacles and contact lenses on driving performance.

Community Eye Health. (2006). How to prescribe spectacles for presbyopia, 19(57), 12-13.

Cited, R. (2004). (12) United States Patent, 2(12).

Ellison, A. (2012). Prismatic displacement effect of progressive multifocal glasses on fall risk in elderly people. 
Gime, A. (2008). Influence of vision distance and lens design in presbyopic user preferences, 38, 1-8. http://doi.org/10.1016/j.ergon.2007.07.006

Gispets, J., Pujol, J., \& Vilaseca, M. (2011). Task oriented visual satisfaction and wearing success with two different simultaneous vision multifocal soft contact lenses, 4(3), 76-84.

Grosvenor, T. P (2007). Primary Care Optometry $5^{\text {th }}$ Edition. Elsiever Health Sciences. Philadephia, USA.

Han, Susan C., Graham, A. D., \& Lin, M. C. (2011). Clinical Assessment of a Customized Free-Form Progressive Add Lens Spectacle, 88(2), $234-243$.

Hiraoka, T., Okamoto, C., Ishii, Y., Kakita, T., Okamoto, F., Takahashi, H., \& Oshika, T. (2009). Patient Satisfaction and Clinical Outcomes After Overnight Orthokeratology, 86(7), 875-882.

Hendicott, P. L. (2007). Spatial perception and progressive addition lenses.

Hons, S. W. F. (2008). OPTOMETRY Progress in the spectacle correction of presbyopia. Part 2: Modern progressive lens technologies, (May), $251-264$. http://doi.org/10.1111/j.1444-0938.2008.00246.x

Hsu, W., Liu, Y., \& Cheng, Y. (2012). Design, fabrication, and metrology of ultra-precision optical freeform surface for progressive addition lens with B-spline description. http://doi.org/10.1007/s00170-012-3901-1

Laviers, H. R., Omar, F., Jecha, H., Kassim, G., \& Gilbert, C. (2009). Visual Psychophysics and Physiological Optics Presbyopic Spectacle Coverage, Willingness to Pay for Near Correction, and the Impact of Correcting Uncorrected Presbyopia in Adults in Zanzibar, East Africa, 1234-1241. http://doi.org/10.1167/iovs.08-3154

Leary, C. I. O., \& Evans, B. J. W. (2003). Criteria for prescribing optometric interventions : literature review and practitioner survey, (November 2002), 429-439.

Lynn, J. (1998). Progressive addition spectacle lenses : Design preferences and head movements while reading.

Malinovska, O., \& Majerova, H. (2015). Typhlotechnics for Persons with Visual Impairment and Quality of Life. Procedia - Social and Behavioral Sciences, 171, 438441. https://doi.org/10.1016/j.sbspro.2015.01.144

Markovits, A., Reddix, M., O"Connell, S., \& PD Collyer. (1995). PAL"s increase the combined zone of near and intermediate correction and eliminate visible lines in the lens (Fig. 1). This intermediate zone of changing power (narrow, clear area in PAL lens, Fig. 1), is referred to as the transition channel. The spheric.

Marmamula, S., Ravuri, L. V. C. S., Boon, M. Y., \& Khanna, R. C. (2013). Spectacle Coverage and Spectacles Use among Elderly Population in Residential Care in the South Indian State of Andhra Pradesh, 2013, 12-17.

McDonnell, P. J., Lee, P., Spritzer, K., Lindblad, A. S., \& Hays, R. D. (2003). Associations of presbyopia with vision-targeted health-related quality of life. Archives of Ophthalmology, 121(11), 1577-1581. https://doi.org/10.1097/00132578-200404000-00020

Meister, D. J., \& Fisher, S. W. (2008). Progress in the spectacle correction of presbyopia. Part 1: Design and development of progressive lenses.

Mok, A. K., Chung, C. S., \& Kwok, T. W. (2011). A simple clinical test for the perception of progressive addition lens peripheral image blur. A pilot study, 4(1), 30-34.

Pope, D. R. (2000). Progressive Addition Lenses : History, Design, Wearer Satisfaction and Trends. OSA TOPS Vol. 35 Vision Science and Its Applications, 35, 342357.

Patel, I., West, S. K., West, S. K., \& Ophthalmology, E.-M. P. of P. (2007). Presbyopia: prevalence, impact, and interventions.

Community
http://www.ncbi.nlm.nih.gov/pubmed/17971909\%5Cnhttp://www.pubmedcentral.nih.gov/articlerender.fcgi?artid=PMC2040246

Retrieved

from

S.E Odjimogho. (2004). SURVEY ON PROBLEMS ASSOCIATED WITH THE USE OF PROGRESSIVE ADDITION LENSES ( PAL ), 11, 16-19.

Savio, G., Concheri, G., \& Meneghello, R. (2011). Parametric Modeling of Free-Form Surfaces for Progressive Addition Lens, 167- 176.

Sheedy, J. E. (2004). Progressive addition lenses--matching the specific lens to patient needs. Optometry (St. Louis, Mo.), 75(2), 83102. https://doi.org/10.1016/S1529-1839(04)70021-4

Sheedy, J., Hardy, R. F., \& Hayes, J. R. (2006). Progressive addition lenses - Measurements and ratings. Optometry, 77(1), 23- 39. https://doi.org/10.1016/j.optm.2005.10.019

Spencer, L. W., \& Ciuffreda, K. J. (2002). Assessing Visual Performance with Progressive, 79(8), 502-505.

Spaulding DH., (1981). Patient preference for a progressive addition multifocal lens (Varilux2) vs a standard multifocal lens design (ST-25). J Am Optom Assoc. 52(10):789-94

Suemaru J1, Hasebe S, Ohtsuki H. (2008) Visual symptoms and compliance with spectacle wear in myopic children: double-masked comparison between progressive addition lenses and single vision lenses. Acta Med Okayama. 62(2):109-17.

Walsh, G. (2001). The products we rely on - Part 5, 35-40. 
Wahab, M. H. A., \& Zuhardi, A. F. A. (2013). Human Visual Quality: Art Gallery Exhibition. Procedia - Social and Behavioral Sciences, 101, 476-487. https://doi.org/10.1016/j.sbspro.2013.07.221

Werner, L., Trindade, F., Pereiera, F., \& Werner, L. (2000). Physiology of Accommodation and Presbyopia. Arquivos Brasileiros De Oftalmologia, 63(6), 503-509. https://doi.org/10.1590/S0004-27492000000600011 